Татьяна КОМАРОВСКАЯ

\author{
ЦЕНТР АМЕРИКАНИСТИКИ \\ ПРИ БЕЛОРУССКОМ ГОСУДАРСТВЕННОМ \\ ПЕДАГОГИЧЕСКОМ УНИВЕРСИТЕТЕ ИМЕНИ \\ МАКСИМА ТАНКА
}

UDC 82-991

DOI 10.22455/2541-7894-2018-4-341-344

\author{
Tatiana KOMAROVSKAYA
}

\title{
AMERICAN CENTRE AT MAXIM TANK BELARUSIAN STATE PEDAGOGICAL UNIVERSITY
}

The American Center at Maxim Tank Belarusian State Pedagogical University was created in 1994 by Dr. Tatiana Komarovskaya. Its mission is to promote within and beyond the University public interest and understanding of history, culture and literature of the United States. AC hosts seminars, lectures, workshops, and conferences that attract students, scholars and public figures. AC is famous for its American studies programs (that include classes and research projects for undergraduate $\&$ graduate students, postdoctoral fellows and reputed scholars), as well as for a wide range of its cultural and educational activities.

(c) 2018 Татьяна Евгеньевна Комаровская (доктор филол. наук, профессор; Белорусский государственный педагогический университет им. Максима Танка, Минск, Беларусь) komar37@mail.ru

(C) 2018 Tatiana Ye. Komarovskaya (Doctor Hab. in Philology, Professor; Maxim Tank Belarusian State Pedagogical University, Minsk, Belarus) komar37@mail.ru 
Центр американистики при Белорусском государственном педагогическом университете имени Максима Танка существует с 1994 года. Он был создан мной сразу после защиты докторской диссертации ${ }^{1}$.

Это была пора прекрасных отношений Республики Беларусь с Соединенными Штатами Америки; посольство США было представлено людьми, всячески приветствовавшими развитие американо-белорусских отношений и помогавшими этому развитию по всем направлениям. Раз в неделю я проводила занятия со своими студентами в Американском информационно-культурном центре (АИКЦ), используя его богатые информационно-технические возможности. К сожалению, уже в начале нового тысячелетия эта деятельность начала сворачиваться. И все же в нашей стране проходили различные международные конференции, на которых американистика была достаточно хорошо представлена. На этих конференциях выступали известные американские профессора - политологи, историки, литературоведы, специалисты по гендерной тематике. Особенно значительными были конференции Женского негосударственного института «Энвила», проводившиеся ежегодно с конца 1990-х в течение всего первого десятилетия нового века, в которых специалисты нашего центра принимали активное участие.

С начала 1990-х годов наш Центр проводил научные конференции по проблемам американистики совместно с Центром американистики Минского лингвистического университета, которым руководит Юрий Викторович Стулов. В дальнейшем конференции, организованные нашим Центром, стали автономными. Так, в 1998 г. прошла Республиканская научная конференция «Мир глазами женщины». В ней принял участие известный американский литературовед профессор Сэмюэл Коэл, который прибыл в университет по приглашению нашего Центра для чтения студентам спецкурсов по современной американской литературе. Это начинание стало доброй традицией: в 2000-м, 2004-м и 2007-м гг. в международных конференциях Центра обязательно принимали участие американские профессора. Эти конференции назывались «Американистика как предмет научного познания» (2000, 2004) и «Актуальные проблемы современной американистики» (2007). По итогам каждой конференции публиковался сборник материалов.

Увы, изменения на политическом уровне заставили белорусскую американистику искать новые формы реализации.

1 T.Е. Комаровская. Проблемы поэтики исторического романа США ХХ века. Дисс. на соискание уч. степени доктора фиол. наук. М., 1994. 


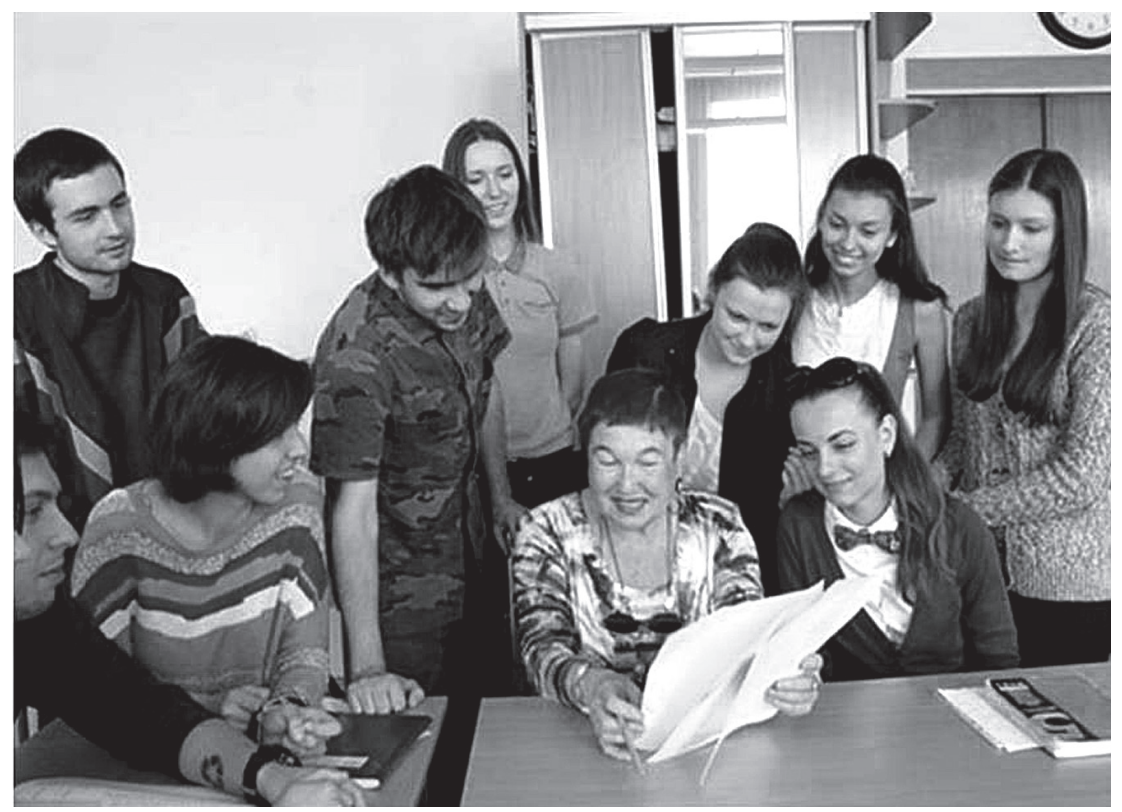

T.E. Комаровская ведет занятия в Американском Центре

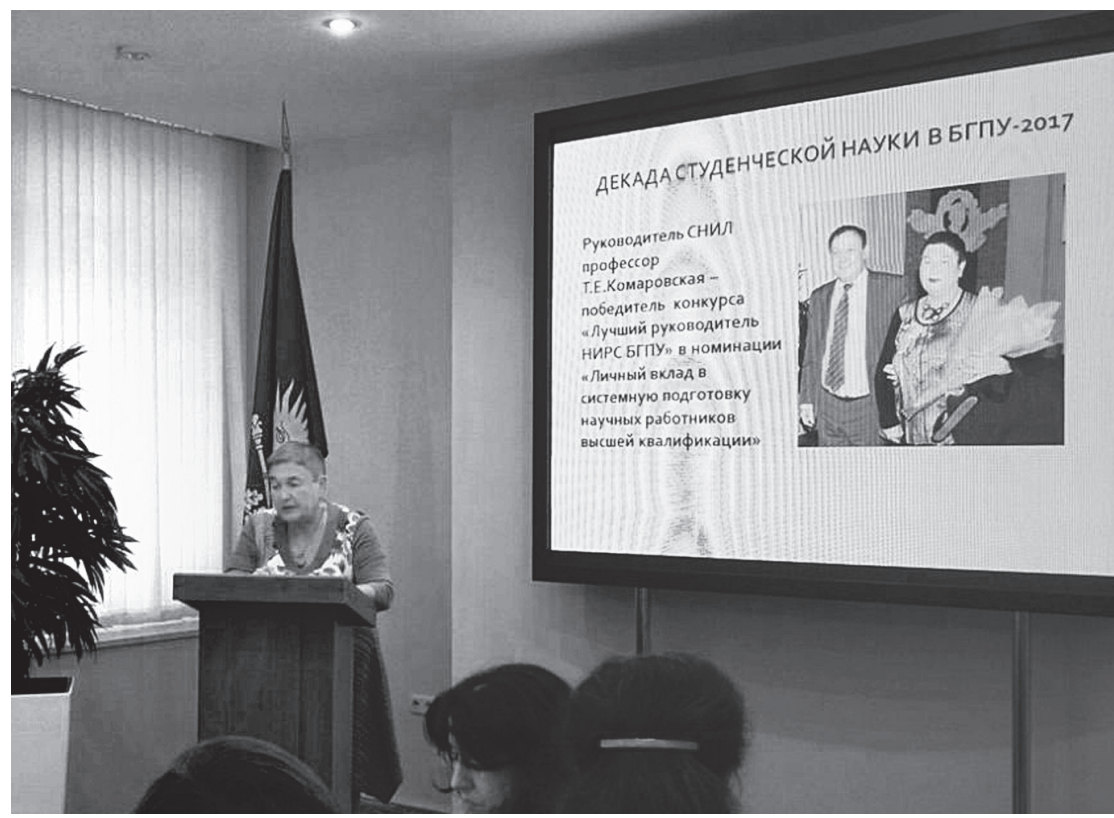

Дни студенческой науки в Американском Центре 
Сейчас в Центре американистики ведется учебная, научная и просветительская работа. По проблемам американистики читаются спецкурсы, проводятся спецсеминары, студенты пишут курсовые и дипломные работы по американской литературе. В последние лет десять в учебные планы БГПУ удалось внедрить дисциплины, основанные на углубленном изучении проблем американского социума и культуры, «Аксиологические и художественные аспекты литературного произведения» (на материале литературы США) и «Современное зарубежное литературоведение» -- курс, посвященный рецепции американским литературоведением западно-европейских литературоведческих теорий $\mathrm{XX}$ века. Лучшие студенты в дальнейшем поступают в магистратуру и аспирантуру и работают над научными темами по литературе США.

Научная и просветительская деятельность Центра американистики осуществлялась сначала через научный студенческий клуб по зарубежной литературе, который затем превратился в Студенческую научно-исследовательскую лабораторию. К настоящему времени по проблемам американской литературы под моим руководством защитилось 10 аспирантов, готовятся еще 3 кандидатские диссертации. Темы некоторых из них - «Соотношение массовой и “серьезной” литературы в художественном дискурсе США» (Г.А. Артамонов); «Творчество Тони Моррисон в контексте литературы США второй половины XX века» (Т.В. Кузьмич); «Национальные и социальные аспекты творчества Элис Уокер» (Н.В. Насон); «Человек и природа в американской и белорусской прозе XX века» (О.В. Гниломедова). Таким образом, благодаря деятельности нашего Центра американистики, в Беларуси создана научная школа по изучению литературы США.

Центр за все годы своей работы провел множество интересных и познавательных мероприятий просветительского характера: организовывались многочисленные встречи, беседы, лекции, в которых принимали участие американские профессора Сэмюэл Коэл, Коллет Морроу, Сэмюэл Оуклэнд и др.

Исследования американской литературы, которые ведутся в нашем Центре, высоко ценятся в Академии наук Республики Беларусь и Белорусском государственном университете, с которыми Центр тесно сотрудничает. 